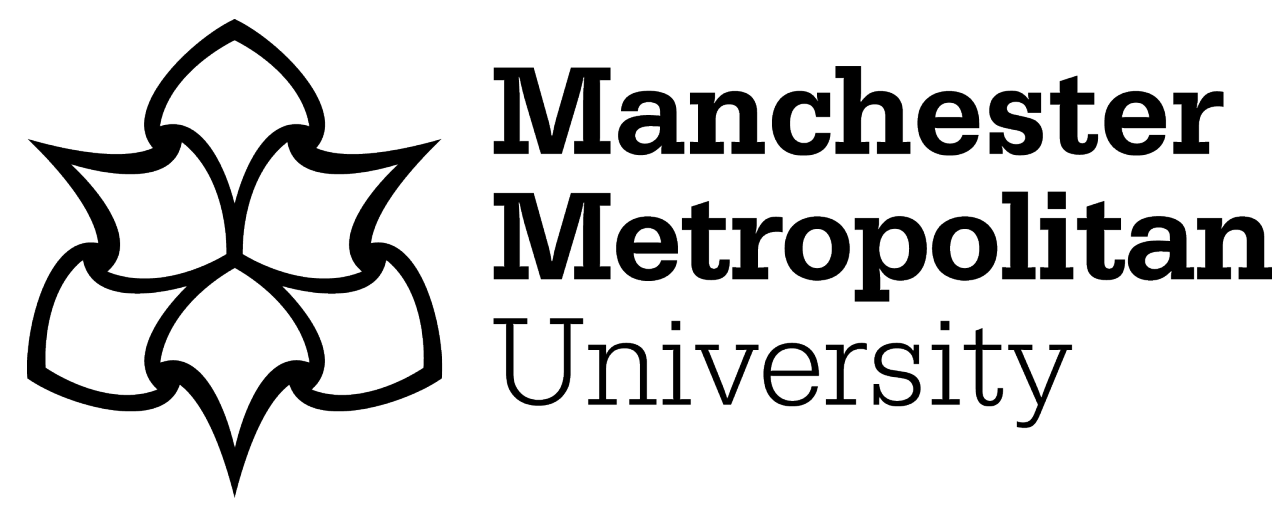

Kong, Wenwen, Huang, Suiliang, Shi, Feifei, Yang, Zhenjiang, Feng, Yibei, Khatoon, Zobia, Zhou, Jian Guo and Xiao, Yao (2020) Study on release kinetics of nitrogen and phosphorus from fish feed. Aquaculture Research, 51 (8). pp. 3216-3229. ISSN 1355-557X

Downloaded from: https://e-space.mmu.ac.uk/626145/

Version: Accepted Version

Publisher: Wiley

DOI: https://doi.org/10.1111/are.14656

Please cite the published version 


\title{
Study on release kinetics of nitrogen and phosphorus from fish feed
}

\author{
Wenwen Kong $^{1,2}$ | Suiliang Huang ${ }^{1}$ (D) | Feifei Shi ${ }^{1}$ | Zhenjiang Yang ${ }^{1}$ | Yibei Feng ${ }^{1}$ | \\ Zobia Khatoon $^{1}$ | Jianguo Zhou ${ }^{3}$ | Yao Xiao ${ }^{1}$
}

\begin{abstract}
${ }^{1}$ Key Laboratory of Pollution Processes and Environmental Criteria of Ministry of Education, Numerical Simulation Group for Water Environment, Tianjin Key Laboratory of Remediation and Pollution Control for Urban Ecological Environment, College of Environmental Science and Engineering, Nankai University, Tianjin, China

${ }^{2}$ Tianjin Key Laboratory of Clean Energy and Pollution Control, School of Energy and Environmental Engineering, Hebei University of Technology, Tianjin, China

${ }^{3}$ Department of Computing and Mathematics, Manchester Metropolitan University, Manchester, UK
\end{abstract}

\section{Correspondence}

Suiliang Huang and Wenwen Kong, Key Laboratory of Pollution Processes and Environmental Criteria of Ministry of Education, Numerical Simulation Group for Water Environment, Tianjin Key Laboratory of Remediation and Pollution Control for Urban Ecological Environment, College of Environmental Science and Engineering, Nankai University, Tianjin 300350, China. Email: slhuang@nankai.edu.cn (S. H.); 2019914@hebut.edu.cn (W. K.)

Funding information

National Natural Science Foundation of China, Grant/Award Number: 11672139, 4181101396 and 5181101344; Chinapoland science and technology cooperation committee regular meeting exchange program, Grant/Award Number: 37-14; Natural Science Foundation of Tianjin City, Grant/Award Number: 18YFZCSF00510

\begin{abstract}
Nitrogen and Phosphorus are the major end products of fish feed loading and affect the water environment as a whole. A magnetic stirrer was used to simulate the intensity of water flow by using different stirring strengths $(0,600,1,200 \mathrm{rpm})$, and kinetic experiments on nutrients release from different fish feed $(0.2500$ and $0.5000 \mathrm{~g}$ ) were performed. Results have shown that total phosphorus (TP) increase rapidly and become stable in about $96 \mathrm{hr}$, while orthophosphate $\left(\mathrm{PO}_{4}^{3-}-\mathrm{P}\right)$, total nitrogen ( $\mathrm{TN}$ ) and ammonia nitrogen $\left(\mathrm{NH}_{4}^{+}-\mathrm{N}\right)$ increase relatively slowly and gradually reach stable from 200, 300 and $300 \mathrm{hr}$ respectively. Both released contents of unit weight fish feed (i.e. released nutrients contents) and released nutrients concentrations in the condition of stirring were higher than those in the static condition. All of the pseudo-first-order, pseudo-second-order and Elovich kinetic models can be used to describe variations of released $\mathrm{TP} \mathrm{PO}_{4}^{3-}-\mathrm{P}, \mathrm{TN}$ and $\mathrm{NH}_{4}^{+}-\mathrm{N}$ contents with time, while the pseudo-first-order kinetic and Elovich kinetic models give better results with $R^{2}=.66-.99$ and $R^{2}=.57-.99$ respectively. Variance analysis showed that both stirring strength and fish feed type have significant effects on released TP, TN and $\mathrm{NH}_{4}^{+}-\mathrm{N}$ contents $(p<.05)$, while fish feed dosage has no significant effects $(p>.05)$. In addition, only the fish feed type does have significant effects on $\mathrm{PO}_{4}^{3-}-\mathrm{P}$ contents $(p<.05)$. In sum, the release kinetics and the factors related to the release of nutrients from fish feed are essential in planning strategies of nutrient management and pollution control.
\end{abstract}

\section{KEYWORDS}

fish feed, nitrogen, phosphorus, release kinetics, stirring strength

\section{1 | INTRODUCTION}

Fish feed and faeces are known to be the most intensive wastes of aquaculture systems resulting in enriching the nutrient pool of receiving water (Bartozek, Bueno, \& Feiden, 2016; Borges, Train, \& Dias, 2010; Huang, Wu, et al., 2016). During intensive production of fish in fish cages, the uneaten feed is released directly into the environment and may cause negative ecological effects on the surrounding water (Wang et al., 2013). The pollution from the aquaculture industry has restricted sustainable fishery production (Amirkolaie, 2011; Wen, Zhang, \& Wen, 2000). Penczak, Galicka, and Molinski (1982) studied the feeding of rainbow trout in freshwater cages and found that $30 \%$ of the dry feeds are not used. Phosphorus in aquaculture water is mainly released from feeding feed, and with the extension of the breeding cycle, the fish feed in water cannot be fully assimilated by the organism, resulting in the accumulation of phosphorus in the water 
(Zhang, Gu, Li, Song, \& Zhou, 2015). Meanwhile, nitrogen is also the essential nutrient incorporated in formulated fish feed for achieving efficient growth of fish (Wang, Wen, \& Chai, 2004). Amirkolaie (2011) believed that aquacultural waste may be present in both solid and liquid form: solid waste is mainly derived from residual fish feed and fish excreta; dissolved waste includes nitrogen, phosphorus and COD, partly directly from fish waste and partly from the further decomposition of solid waste.

The residual fish feed is the main pollutant in aquaculture water (Akhan \& Gedik, 2011; Amirkolaie, 2011; Liu, Cui, \& Liu, 1997), and its impact on environment has received much attention (Akhan \& Gedik, 2011; Amirkolaie, 2011; Kibria, Nugegoda, Fairclough, \& Lam, 1997; Nędzarek, Tórz, \& Stepanowska, 2009). The fractional composition of nutrients and the release of nutrients from fish feed in the rearing of Australian native fish silver perch Bidyanus bidyanus fingerling are investigated, and both temperature and $\mathrm{pH}$ affected the release of nutrients from fish feed and faeces (Kibria et al., 1997). Wu, Huang, Zang, Du, and Scholz (2012) studied the effects of the quantities and size of fish feed on the nutrients release from fish feed, and the results showed that the nitrogen and phosphorus concentrations in water increase with increasing dosages of fish feed, while the size of fish feed has no significant effect on nitrogen and phosphorus concentrations with the same fish feed dosage (Wu et al., 2012). Huang's, Kong, Yang, Yu, and Li (2019) experiment also showed that fish feed release a large amount of nitrogen and phosphorus after they enter the water, and further promote the growth of Microcystis aeruginosa, and the density of M. aeruginosa increases with increasing dosages of fish feed.

In general, water disturbances and changes of water flow conditions exist in natural aquaculture water such as rivers, lakes and reservoirs. Methods of on-site observation, indoor experiments and numerical simulation have been used to study the effects of turbulent action, wind and wave disturbance, hydrodynamic action on sediment adsorption, desorption and release of pollutants (Gao, Sun, \& Zhang, 2007; Huang et al., 2015; Huang, 2001, 2003; Sun, Qin, \& Zhu, 2007; Sun et al., 2016; Xia, Zhang, Jiang, \& Nie, 2014; Xia, Zhang, \& Nie, 2014). Huang (2001, 2003) believed that the turbulence intensity has a direct impact on the movement of particulate matter in water, the concentration of suspended particulate matter and the composition of the particle size, which has a significant impact on the release or desorption of pollutants off sediments. Huang, $\mathrm{Xi}$, et al. (2016) and Huang, Wu, et al. (2016) also observed that the eutrophication level of lakes is sensitive to dynamic water flow (i.e. disturbance) due to the small depth in shallow lakes and high content of nutrients in riverbed sediment.

Nutrient levels are important factors affecting the sustainability of aquaculture water (Akhan \& Gedik, 2011), while hydrodynamic processes are important factors affecting nutrients migration and transformation (Huang et al., 2015; You et al., 2007). At present, the release of nitrogen and phosphorus from fish feed has become a consensus (Ackefors \& Enell, 1994; Akhan \& Gedik, 2011; Gao, Xu, \& Liu, 2008; Wu et al., 2012), and the influence of hydraulic conditions on release of pollutants from sediment has also been studied (Huang et al., 2015; Huang, 2003; Xia, Zhang, Nie, et al., 2014). However, the influence of hydraulic conditions on the release of nitrogen and phosphorus from fish feed remains to be further explored.

It is noted that the nutrient release process of fish feed is often described by empirical equations such as quadratic equations and exponential equations (Akhan \& Gedik, 2011; Huang \& Kong, 2017; Kibria et al., 1997). The research conducted by Huang and Kong (2017) have shown that the exponential equation describing the variations of TP concentrations with time from fish feed is the same as the pseudo-first-order kinetic equation. Generally, some kinetic models such as the pseudo-first-order, pseudo-second-order and Elovich kinetic models are mostly used to describe adsorption (or uptake) and desorption (or release) kinetics based on the solution concentrations (Gera, Yewalkar, Nene, Kulkarni, \& Kamble, 2016; Ho, 2006a, 2006b; Qian, Chu, Zhang, Liu, \& Wan, 2019; Ranjbar \& Jalali, 2014). The pseudo-second-order equation (Ho, 2006a) and Elovich equation (Qian et al., 2019; Ranjbar \& Jalali, 2014) are believed to be an empirical equation. The release of nutrients from sediment is often described by pseudo-first-order kinetic model, Elovich kinetic model and so on (Cao \& Tao, 1999; Chien \& Clayton, 1980; Morin \& Morse, 1999; Wang, Wang, Jin, Zhang, \& Zhu, 2007). However, whether these kinetic models are valid for describing the release of nutrients from fish feed has not been discussed. Thus, pseudo-first-order, pseudo-second-order and Elovich kinetic models are applied to discuss the release of nutrient from fish feed.

Polyculture of Chinese carp use large amount of commercial compound freshwater fish feed. Nutrients contents of different types' fish feed might vary slightly with location source, season and so on. Therefore, compound freshwater fish feed from three different manufactures with two dosages were selected to investigate the applicability and universality of these kinetic models in describing the nutrients release from fish feed. Meanwhile, a magnetic stirrer was used to simulate different hydrodynamic conditions by using different stirring strength, and further the effects of stirring intensity on the nutrients release was also explored. The study is beneficial to understand the secondary pollution problem of residual fish feed, to provide scientific basis for improving the utilization rate of aquaculture fish feed, and to prevent and control the eutrophication of aquaculture water.

\section{2 | MATERIAL AND METHODS}

\subsection{Experimental materials}

Commercial adult fish feed was selected from Huaian Tongwei Company Limited, Hebei Panda Feed Company Limited and Zhongshan City Taishan Feed Company Limited, and the three fish feeds were named as HT fish feed, HP fish feed and ZT fish feed respectively. All these fish feeds are used for polyculture of freshwater fish in freshwater bodies such as lakes, reservoirs, ponds and so on. These fish feeds were crushed and sieved through Taylor pore 
size of $0.85 \mathrm{~mm}$ before use. Nutritional indicators of these fish feed disclosed by their respective manufacturers are shown in Table 1.

The experimental magnetic stirrer model used in this study was Chi Jiu 84-1 (Shanghai Meiying Instrument and Meter Manufacturing Co., Ltd.).

\section{2 | Batch beaker experiment}

Effects of stirring intensity and fish feed dosage on released nutrients from fish feed were assessed using batch beaker experiments. Three different fish feed samples of 0.2500 and $0.5000 \mathrm{~g}$ of the three fish feed were added into $2 \mathrm{~L}$ beakers containing $1 \mathrm{~L}$ of distilled water respectively. With the same dosage $(0.25$ or $0.50 \mathrm{~g})$ and same type (HT, HP, ZT) of fish feed, magnetic stirrer was used to design three stirring intensities of 0,600, 1,200 rpm, each stirring intensity was set to three parallels. In general, the velocities of water in the beaker will increase with increasing speed of rotation, but it is difficult to measure the velocities during the experimental period.

After the addition of fish feed, samples were analysed at 0, 6, 24, 48, 96, 144, 192, 240, 288, 336, 408, 480 and $624 \mathrm{hr}$. The analytical method of nutrients is based on the 'Water and wastewater monitoring and analysis method' (China's State Environmental Protection Administration, 2002) to monitor total phosphorus (TP), dissolved orthophosphate $\left(\mathrm{PO}_{4}^{3-}-\mathrm{P}\right)$, total nitrogen (TN) and ammonia nitrogen $\left(\mathrm{NH}_{4}^{+}-\mathrm{N}\right)$. The concentrations of TP and $\mathrm{PO}_{4}^{3-}-\mathrm{P}$ were determined by molybdenum antimony spectrophotometry. The TN concentration was determined by ultraviolet spectrophotometry. The TN concentration was determined by sodium reagent spectrophotometry. The experimental results were averaged using parallel samples.

\section{3 | Release kinetics of nutrients from fish feed}

The released nutrients contents of unit weight fish feed, $Q_{t}(\mathrm{mg} / \mathrm{g})$ was determined by using the following equation defined as:

$$
Q_{t}=\frac{\left(C-C_{0}\right) \times V}{m}
$$

For the convenience of discussion, $Q_{t}$ is simplified as 'released nutrients contents', and it can reflect the release ability of nutrients from fish feed when it reaches stable. $C(\mathrm{mg} / \mathrm{L})$ is released nutrients concentrations, and it can reflect water pollution level directly. $C_{0}$ $(\mathrm{mg} / \mathrm{L})$ is background concentration; $V(\mathrm{~L})$ is the solution volume and $m(g)$ is the mass of fish feed added initially. Released nutrients concentrations from fish feed and released nutrients contents of unit weight fish feed are two indicators describing nutrients release.

Three widely used kinetic models, that is pseudo-first-order, pseudo-second-order and Elovich kinetic models, were employed to interpret the kinetic results. Equation 2 is the pseudo-first-order kinetic model.

$$
Q_{t-1}=Q_{e-1}\left(1-e^{-k_{1} t}\right)
$$

in which $Q_{e-1}(\mathrm{mg} / \mathrm{g})$ and $Q_{t-1}(\mathrm{mg} / \mathrm{g})$ are the release nutrient content of unit weight fish feed at the equilibrium and at any time $t$ (hr) time respectively. $k_{1}\left(\mathrm{hr}^{-1}\right)$ is the rate constant of pseudo-first-order kinetic model.

The pseudo-second-order kinetic model is given as follows:

$$
\frac{t}{Q_{t-2}}=\frac{1}{k_{2} Q_{e-2}^{2}}+\frac{t}{Q_{e-2}}
$$

in which $Q_{\mathrm{e}-2}(\mathrm{mg} / \mathrm{g})$ and $Q_{t-2}(\mathrm{mg} / \mathrm{g})$ are also the release nutrient content of unit weight fish feed at the equilibrium and at any time $t(\mathrm{hr})$ time respectively. $k_{2}\left(\mathrm{hr}^{-1}\right)$ is the rate constant of pseudo-second-order kinetic model.

In the present study, Elovich model is used to describe the diffusion process of nutrients from fish feed, and the release process is also divided into a fast phase and a slow phase. Elovich model is written as follows:

$$
Q_{t-3}=\frac{1}{Y} \ln (X Y)+\frac{1}{Y} \ln t
$$

where $X(\mathrm{mg} / \mathrm{g})$ and $Y\left(\mathrm{~g} \cdot \mathrm{hr} \cdot \mathrm{mg}^{-1}\right)$ are constants. The intercept $(1 / \mathrm{Y}) \ln (X Y)$ $(\mathrm{mg} / \mathrm{g})$ coincides with the released quantity during the fast phase (also known as the initial rate), whereas the slope $1 / Y\left(\mathrm{mg} \cdot(\mathrm{g} \cdot \mathrm{hr})^{-1}\right)$ represents the slow release in relation to the duration of second phase. $Q_{t-3}(\mathrm{mg} / \mathrm{g})$ is the release content of unit weight fish feed at any time $t$ (hr).

\section{4 | Data analysis}

\begin{tabular}{|c|c|c|c|c|c|c|c|c|c|}
\hline Fish feed & $\begin{array}{l}\text { Crude protein } \\
(\%)\end{array}$ & Crude fibre (\%) & Crude fat (\%) & $\begin{array}{l}\text { Crude } \\
\text { ash (\%) }\end{array}$ & Calcium (\%) & TP (\%) & $\mathrm{NaCl}(\%)$ & Moisture (\%) & $\begin{array}{l}\text { Lysine } \\
\text { (\%) }\end{array}$ \\
\hline $\mathrm{HT}$ & $\geq 28.0$ & $\leq 12.0$ & $\geq 3.0$ & $\leq 15.0$ & $0.5-2.0$ & $\geq 0.60$ & $0.2-1.5$ & $\leq 12.5$ & $\geq 1.2$ \\
\hline HP & $\geq 28.0$ & $\leq 12.0$ & $\geq 3.0$ & $\leq 18.0$ & $0.5-2.0$ & $\geq 0.80$ & $0.3-1.5$ & $\leq 13.0$ & $\geq 1.3$ \\
\hline $\mathrm{ZT}$ & $\geq 20.0$ & $\leq 17.0$ & $\geq 2.0$ & $\leq 15.0$ & $\leq 2.0$ & $\geq 0.50$ & $\leq 2.0$ & $\leq 12.5$ & $\geq 0.9$ \\
\hline
\end{tabular}

Data processing and statistical analysis were performed using Origin 8.6 and SPSS 19.0.

TABLE 1 Nutritional indicators of fish feed

Note: HP, HP fish feed is produced by Hebei Panda Feed Company Limited; HT, HT fish feed is produced by Huaian Tongwei Company Limited; TP, total phosphorus in fish feed; ZT, ZT fish feed is produced by Zhongshan City Taishan Feed Company Limited. 


\section{RESULTS AND DISCUSSION}

\section{1 | Release kinetics of phosphorus from fish feed}

Phosphorus is a component of chemical compounds in fish feed (Hua \& Bureau, 2006), and the labile form $\left(\mathrm{PO}_{4}^{3-}-\mathrm{P}\right)$ is a majority of phosphorus (Wu et al., 2012). Thus, release kinetics of TP and $\mathrm{PO}_{4}^{3-}-\mathrm{P}$ from fish feed are discussed in this part.

\subsection{1 | Release kinetics of TP from fish feed}

Figure 1 shows the variations of released TP concentrations and released contents in all treatments. Either released TP concentrations or released TP contents increase to the maximum values rapidly in $96 \mathrm{hr}$ from beginning, and became stable afterwards, which is generally consistent with the experimental results of Huang and Kong's (2017) and Wu et al.'s (2012) result. According to Figure 1 and Equation 1, released TP concentrations in treatments with $0.5 \mathrm{~g}$ fish feed were nearly two times higher than those of treatments with $0.25 \mathrm{~g}$ fish feed, while released TP contents of unit weight fish feed in treatments with $0.5 \mathrm{~g}$ fish feed were quite close to those of treatments with $0.25 \mathrm{~g}$ fish feed. Leaching from feeds of southern Bluefin tuna is fast and experiments reached equilibrium within the first hour in Fernandes's, Angove, Sedawie, and Cheshire (2007) study; this may be because the feed for feeding different fish are also different in quality, composition, retention time and so on. A rapid increase in phosphorus release was also detected in both faeces and food samples in first few days and thereafter it is decreased in Akhan and Gedik's (2011) study, which may be due to the reason that microorganisms are abundant in faeces and take up a lot of phosphorus.

From Figure 1, with same fish feed dosage and stirring intensity, the relationship among released TP concentrations and contents of three different fish feed is HT > HP > ZT. As shown in Table 1, HT and HP fish feed have higher crude fat and crude protein than ZT fish feed, it indicates that our results are related to the fish feed nutrition composition and quality. In Nędzarek et al.'s (2009) study, the nutrient emission dada from different fish feed are also different, they believe higher nutrient emission was noted with high fat feed. With same type and dosage of fish feed, either released TP concentrations or released TP contents increase with increasing stirring intensity, following the order $1,200 \mathrm{rpm}>600 \mathrm{rpm}>0 \mathrm{rpm}$ (in Figure 1). Experimental results of Geng, Wang, Wang, Qi, and Wang (2015) demonstrated that phosphorus in sediments has obviously been released under hydrodynamic conditions relative to hydrostatic conditions. Although the composition of fish feed is different from the sediment, the releasing process of TP from fish feed is also affected by hydrodynamic conditions.

The release kinetic model can be used to describe the release of contaminant from sediment in static experiments (Xiao, Cheng, Tang, \& Li, 2015). Wang, Shen, and Ma (2010) studied the kinetics of phosphorus released from rock sources in Chaohu Lake Basin with first-order kinetic model, Elovich kinetic model, weight kinetic model and parabolic kinetic model. Shariatmadari and Jafari (2006) used the first-order, second-order and Elovich kinetic models to describe the kinetics of phosphorus release from the solid phase to the aqueous phase in the soil. However, these models have not been applied in describing the released process of TP from fish feed in previous studies. In the present study, from Table 2 and Figure 1, all of the pseudo-first-order kinetic model, pseudo-second-order kinetic model and Elovich model can describe the variations of TP released from fish feed, and the corresponding correlation coefficients $\left(R^{2}\right)$ are .93-.99, .53-.97, .90-.99. The fitting results of pseudo-first-order and Elovich kinetic models are better. As shown in Table 2, with the same stirring intensity and fish feed dosage, $Q_{e-1}$ and $Q_{e-2}$ of $H T$ is most, $Q_{e-1}$ and $Q_{e-2}$ of HP is next while $Q_{e-1}$ and $Q_{e-2}$ of ZT is smallest, which conforms to experimental results. With the same type and dosage of fish feed, both $Q_{e-1}$ and $Q_{e-2}$ increase with increasing stirring intensity, the fitting result is also well agreement with experimental results. According to the parameters of Elovich kinetic model in Table 2, $(1 / Y) \ln (X Y)$ is obviously higher than $1 / Y$, and $(1 / Y) \ln (X Y)$ increases with increasing stirring intensity, which indicates that the release of TP from fish feed is mainly in fast stage, and released TP contents of unit weight fish feed in fast phase increase with increasing stirring intensity.

Effects of stirring intensity, fish feed dosage and fish feed type on released TP concentrations and released TP contents from fish feed are conducted by variance analysis (Data are shown in Table S1). From Table S1, both the stirring intensity and fish feed types have significant effects on released TP concentrations and contents from fish feed ( $p<.05$ ), while fish feed dosage only has significant effect on released TP concentrations $(p<.05)$ and has no significant effect on released TP contents $(p>.05)$. This happens because the released TP concentrations increase in proportion to the increase in the dosage of fish feed, which conforms to experimental results and Equation 1. In addition, there is no interaction among the stirring intensity, fish feed dosage and fish feed type for released TP concentrations and released TP contents. According to the released TP contents, it can be observed that the release ability of TP from fish feed is related to the hydraulic conditions and the nature (type) of fish feed regardless of the fish feed dosage.

\subsection{2 | Release kinetics of $\mathrm{PO}_{4}^{3-}-\mathrm{P}$ from fish feed}

Variations of released $\mathrm{PO}_{4}^{3-}-\mathrm{P}$ concentrations and released $\mathrm{PO}_{4}^{3-}-\mathrm{P}$ contents with time in each treatment are shown in Figure 2. In static water, both released $\mathrm{PO}_{4}^{3-}-\mathrm{P}$ concentrations and contents increase rapidly during the first $96 \mathrm{hr}$, and then increase slowly and became stable about $200 \mathrm{hr}$, which is consistent with Huang and Kong's (2017) and Wu et al.'s (2012) study. With stirring, both released $\mathrm{PO}_{4}^{3-}-\mathrm{P}$ concentrations and contents increase rapidly during 0-24 hr, and decrease slightly during 24-48 hr, and then continues to increase until they reach stable. Variations of released $\mathrm{PO}_{4}^{3-}-\mathrm{P}$ concentrations (or released $\mathrm{PO}_{4}^{3-}-\mathrm{P}$ contents) are not 

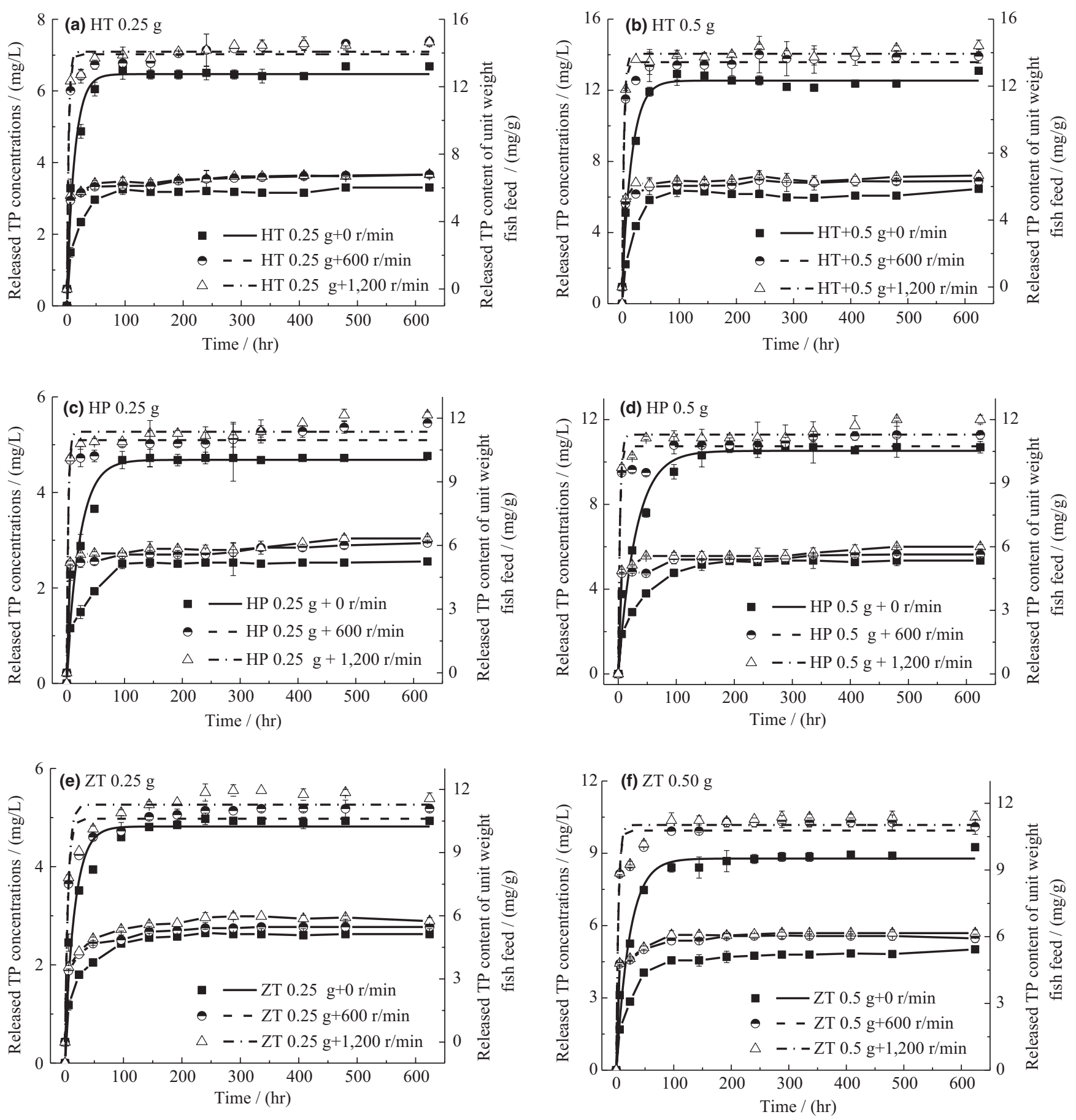

FIGURE 1 Pseudo-first-order kinetic of TP from fish feed

consistent with variations of released TP concentrations (or released TP contents) completely. This may be because variations of TP concentrations (or released TP contents) are also affected by the releasing process of other phosphorus forms such as organic phosphorus, but more detailed reasons need to be further explored. Meanwhile, according to Equation 1 and Figure 2, consistent with results of TP, released $\mathrm{PO}_{4}^{3-}-\mathrm{P}$ concentrations in treatments with $0.5 \mathrm{~g}$ fish feed are nearly two times higher than those of treatments with $0.25 \mathrm{~g}$ fish feed, while released $\mathrm{PO}_{4}^{3-}-\mathrm{P}$ contents in treatments with $0.5 \mathrm{~g}$ fish feed are quite close to those of treatments with $0.25 \mathrm{~g}$ fish feed. Our experimental results indicated that both $\mathrm{TP}$ and $\mathrm{PO}_{4}^{3-}-\mathrm{P}$ released from fish feed occurs rapidly. Thus, to avoid nutrient enrichment of water environment, uneaten fish food should be removed quickly (Akhan \& Gedik, 2011).

In addition, from Figure 3, with the same fish feed dosage and stirring intensity, either released $\mathrm{PO}_{4}^{3-}-\mathrm{P}$ concentrations or released $\mathrm{PO}_{4}^{3-}-\mathrm{P}$ contents from different fish feed conforms that HT fish feed is most, HP is the next while ZT is smallest. With the same fish feed type and dosage, either released concentrations or contents of $\mathrm{PO}_{4}^{3-}-\mathrm{P}$ from fish feed among treatments with different stirring 
TABLE 2 Release kinetics of TP from fish feed

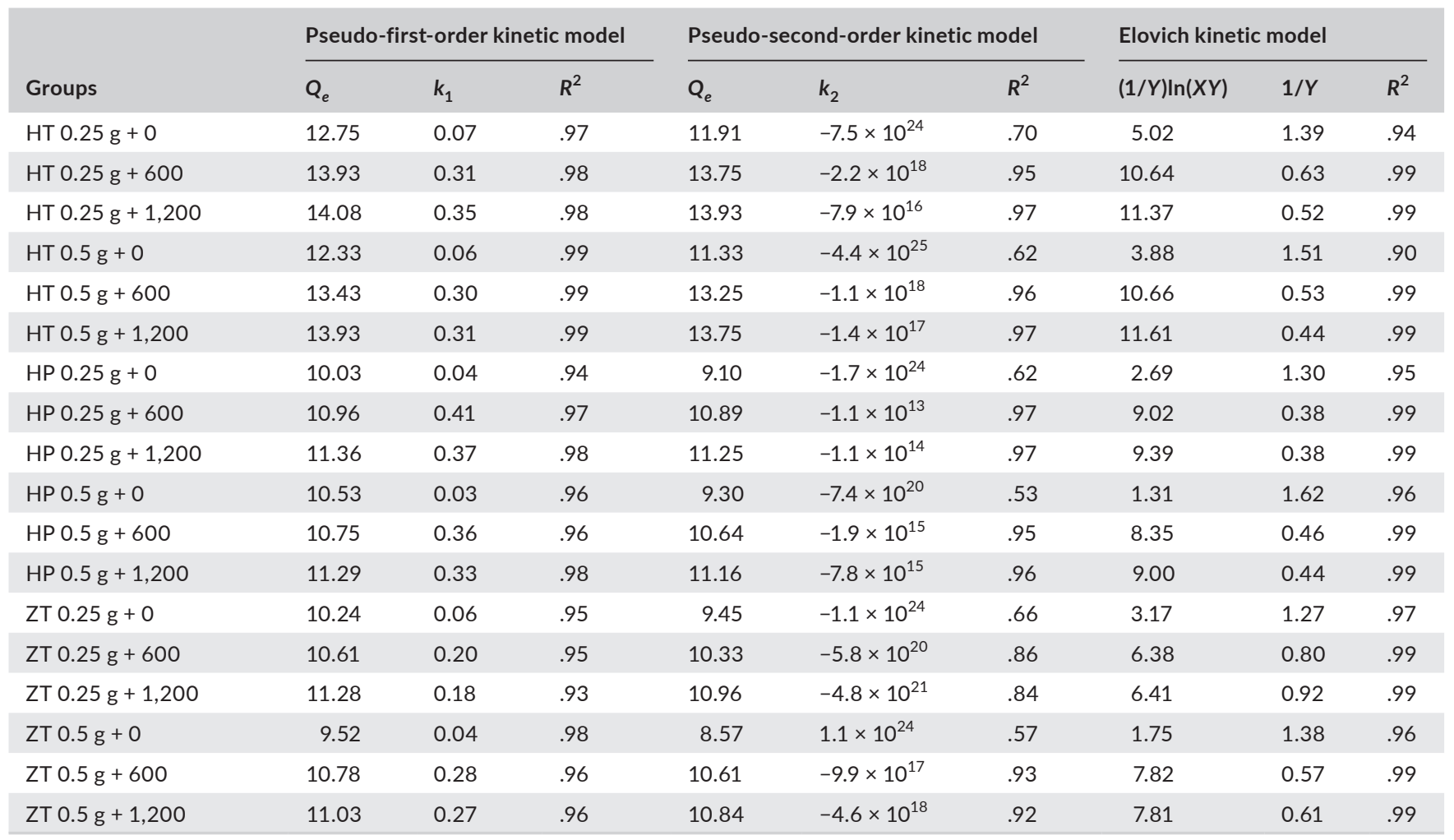

intensities (1,200, 600 and 0 rpm) are quite close. By conducting the in situ experiment, Chao et al. (2011) find that the dissolved nutrients do not increase significantly during the high wind. Geng et al.'s (2015) experimental results show that the total released nutrients amount is larger under dynamic conditions than that of static conditions (such as TP). However, due to turbulence, the water and water-soil interface are oxygenated, and the metal elements such as iron and manganese are adsorbed and dissolved due to oxidation (Geng et al., 2015). Thus, dynamic disturbances only cause total nutrient release and do not necessarily lead to the release of dissolved nutrients (Geng et al., 2015). Zhu, Qin, and Gao (2004) also believed that the reoxygenation process in water is rapid and sufficient during strong winds, and the oxidation conditions are beneficial to the adsorption of phosphorus by particles in water and do not cause significant concentration of dissolved phosphorus in water. In the present experiment, stirring strength also did not significantly increase the released $\mathrm{PO}_{4}^{3-}-\mathrm{P}$ concentrations or contents (in Figure 2), which may be related to the reoxygenation of the water surface during stirring. However, more specific reasons have yet to be explored.

According to fitting results of kinetic models in Table 3 and Figure 2, all of pseudo-first-order kinetic model, pseudo-second-order kinetic model and Elovich kinetic model can describe the variations of released $\mathrm{PO}_{4}^{3-}-\mathrm{P}$ contents well in the present experiment, and the correlation coefficients $\left(R^{2}\right)$ are $.67-.98, .30-.65$ and $.91-$ .97 , respectively, and the fitting result of Elovich model is optimal. According to the fitting results of Elovich kinetic model in Table 3 , $1 / Y$ is higher than $(1 / Y) \ln (X Y)$ when the stirring strength is $0 \mathrm{rpm}$, which indicates that the releasing process of $\mathrm{PO}_{4}^{3-}-\mathrm{P}$ mainly occurs in the slow phase. However, the releasing process of $\mathrm{PO}_{4}^{3-}-\mathrm{P}$ from $\mathrm{HT}$ fish feed is mainly fast phase when the stirring intensity is 600 and $1,200 \mathrm{rpm}((1 / Y) \ln (X Y)>1 / Y)$, and the releasing process of $\mathrm{PO}_{4}^{3-}-\mathrm{P}$ from $\mathrm{HP}$ and $\mathrm{ZT}$ fish feed are mainly slow phase when the stirring intensity is 600 and $1,200 \mathrm{rpm}((1 / Y) \ln (X Y)<1 / Y)$. This may be because the released ability of $\mathrm{PO}_{4}^{3-}-\mathrm{P}$ from fish feed is affected by both fish feed type and stirring intensity. Wang, Shen, et al. (2010) reported that Elovich model can describe a process involving a series of reaction mechanisms, including not only the diffusion of solute at the body or interface, but also the activation and deactivation of the surface. The process with a single reaction mechanism is not suitable, but it is very suitable for processed with large changes in activation energy during the reaction process (such as sediment and other processes). These kinetic models have not been applied in describing variations of $\mathrm{PO}_{4}^{3-}-\mathrm{P}$ concentrations released from fish feed, but the results showed that these kinetic models are suitable and consistent with variations of $\mathrm{PO}_{4}^{3-}-\mathrm{P}$ from sediments or soil. Shariatmadari and Jafari (2006) studied the release kinetics of phosphorus from soil using soil contaminated with $\mathrm{KH}_{2} \mathrm{PO}_{4}$ solution, and the results also show that the Elovich model can describe the kinetic data well. Chien and Clayton (1980) also uses Elovich model to better fit the process of releasing phosphate from sediments in the lake.

Variance analysis of released $\mathrm{PO}_{4}^{3-}-\mathrm{P}$ concentrations and contents from fish feed is given in Table S1. From Table S1, it is indicated that both fish feed dosage and fish feed type have 

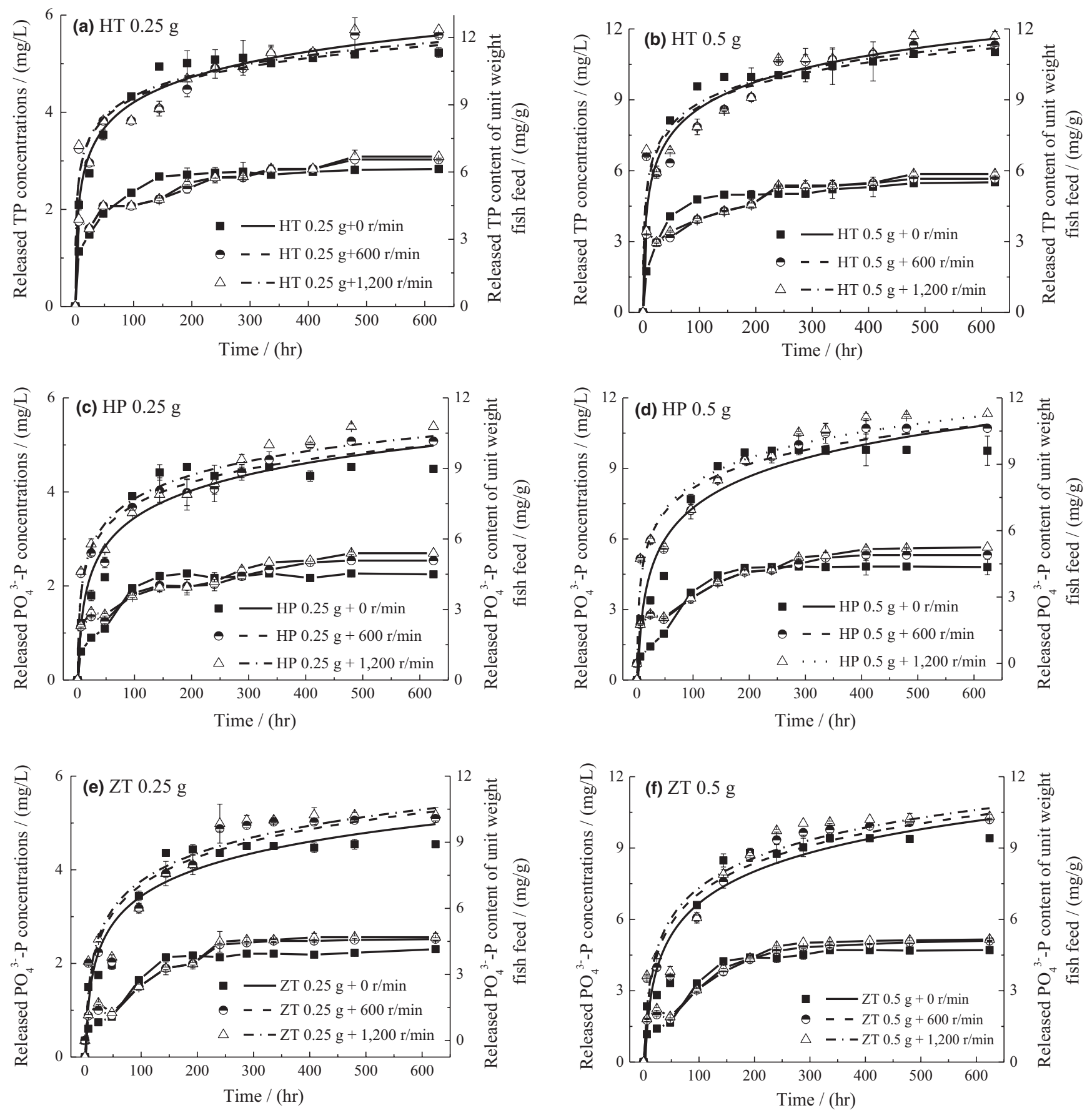

FIGURE 2 Elovich kinetic of $\mathrm{PO}_{4}^{3-}-\mathrm{P}$ from fish feed

significant effects on released $\mathrm{PO}_{4}^{3-}-\mathrm{P}$ concentrations $(p<.05)$, while only fish feed type has a significant effect on the released $\mathrm{PO}_{4}^{3-}-\mathrm{P}$ contents $(p<.05)$. This is because the released $\mathrm{PO}_{4}^{3-}-\mathrm{P}$ concentrations increase proportionally with increasing of fish feed dosage (Wu et al., 2012). In addition, there is no interaction among the stirring intensity, fish feed dosage and fish feed type $(p>.05)$. In addition, $\mathrm{PO}_{4}^{3-}-\mathrm{P}$ is the main component of TP in fish feed, average released $\mathrm{PO}_{4}^{3-}-\mathrm{P}$ concentrations account for $68 \%-85 \%$ of average released TP concentrations (Data are shown in Table S2).

\section{2 | Release kinetics of nitrogen from fish feed}

\subsubsection{Release kinetics of TN from fish feed}

Figure 3 shows the effect of stirring intensity, fish feed type and fish feed dosage on released TN concentrations (or released TN contents) from fish feed. As shown in Figure 3, under non-stirring condition, released TN concentrations (or released TN contents) increase gradually during $0-300 \mathrm{hr}$ and keep stable in the following hours, the results conform to Wu et al.'s (2012) experimental results. 

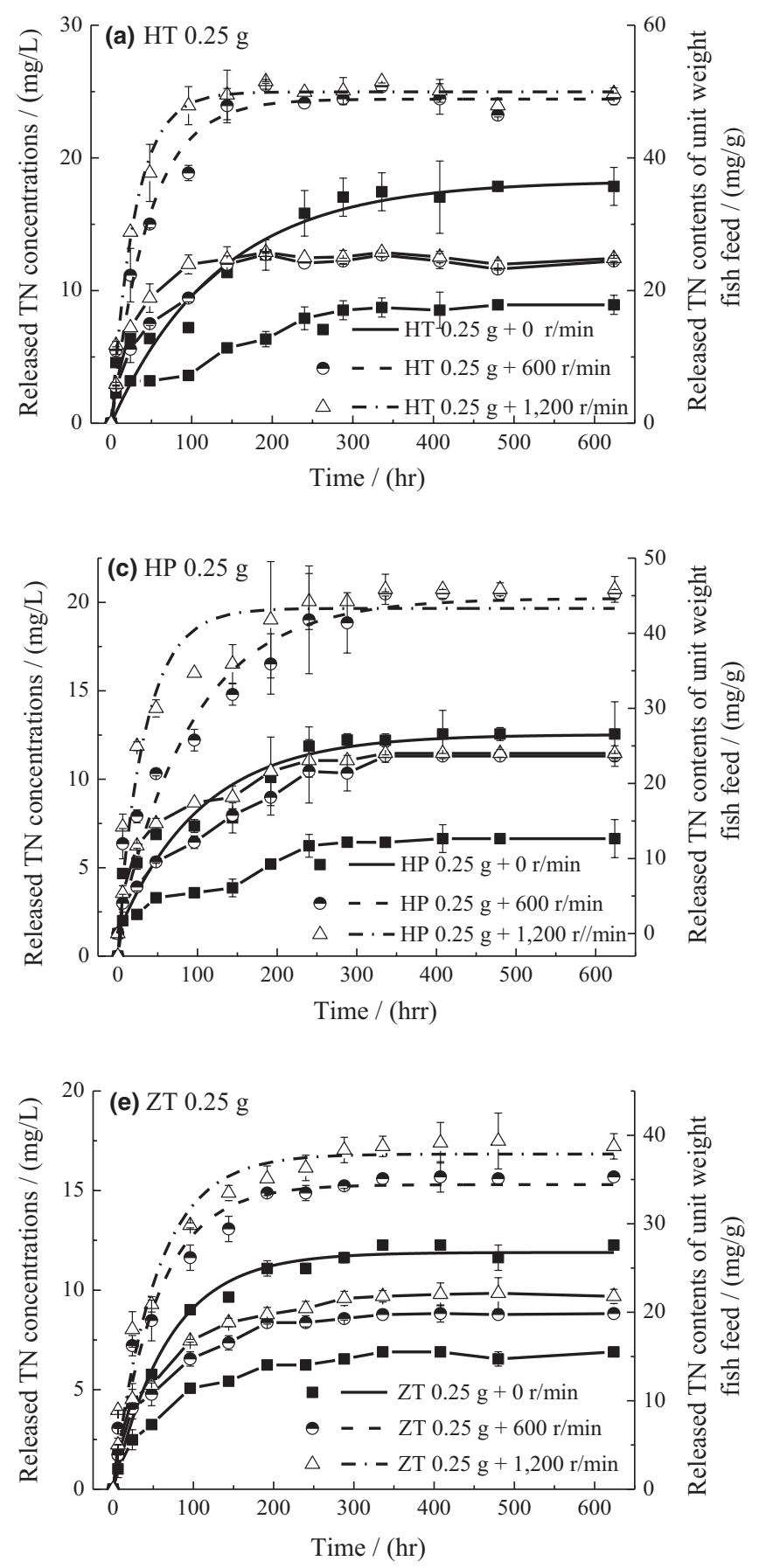

FIGURE 3 Pseudo-first-order kinetic of TN from fish feed

Under stirring condition, fish feed is suspended in a large amount in the initial stage of water agitation, and released TN concentrations (or released TN contents) increase rapidly to the maximum value with time during $0-300 \mathrm{hr}$, and also keep stable afterwards. Either released TN concentrations or released TN contents increase with increasing of stirring intensity. In addition, consistent with variations of TP and $\mathrm{PO}_{4}^{3-}-\mathrm{P}$, released TN concentrations in treatments with $0.5 \mathrm{~g}$ fish feed are about two times higher than those of treatments with $0.25 \mathrm{~g}$ fish feed, and released TN contents in treatments with $0.5 \mathrm{~g}$ fish feed are equals to those of treatments with $0.25 \mathrm{~g}$ fish feed generally.
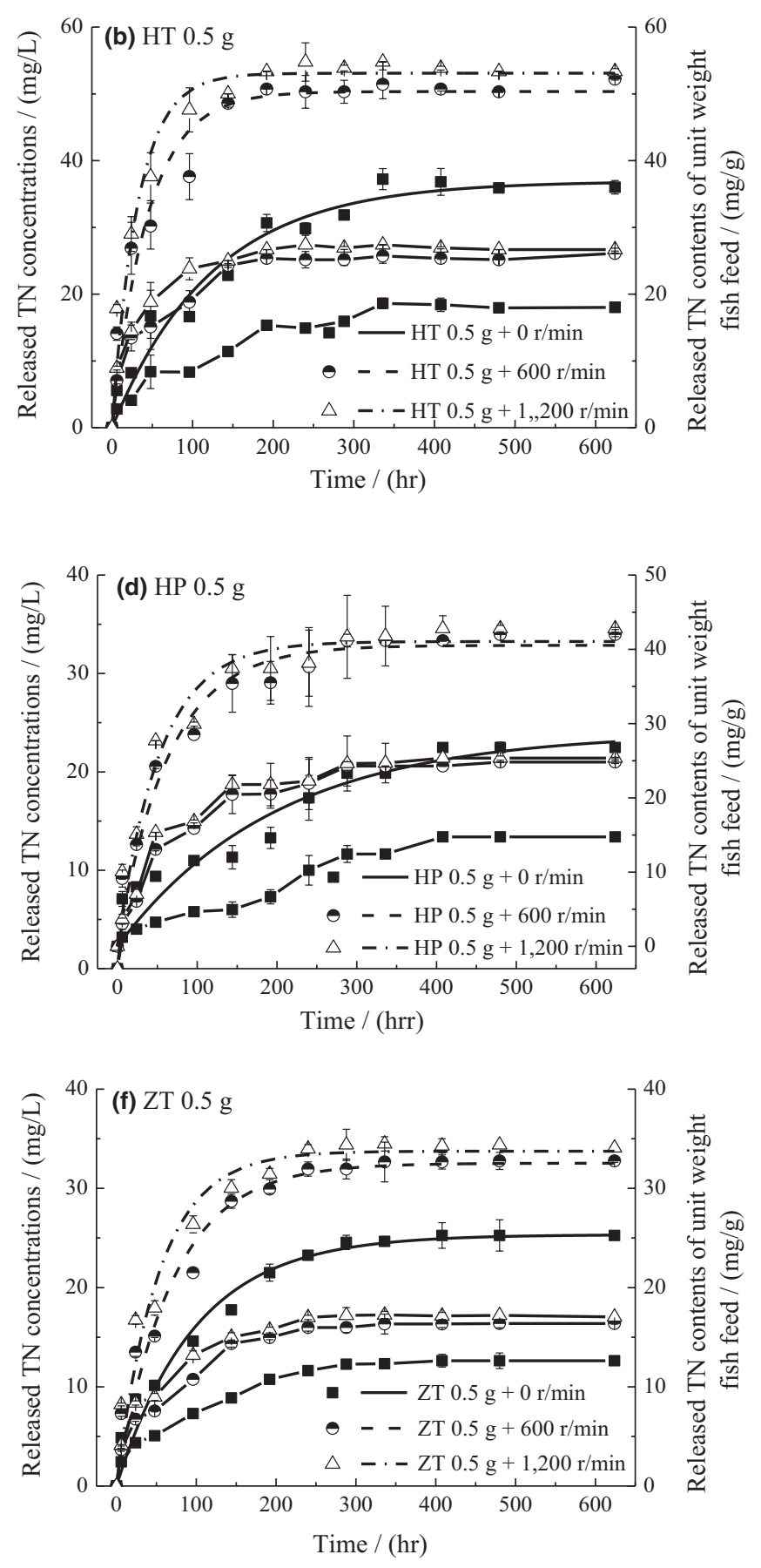

In addition, released TN contents of unit weight fish feed are similar under strong stirring intensity (1,200 rpm) and weak stirring intensity $(600 \mathrm{rpm})$, and both are higher than non-stirring conditions (0 rpm). Consistent with the experimental TP and $\mathrm{PO}_{4}^{3-}-\mathrm{P}$ concentrations (or contents), released TN concentrations (or contents) from HT fish feed are highest, followed by HP fish feed, and ZT fish feed with same fish feed dosage and stirring intensity. The result also conforms to the crude protein and crude fat composition of three fish feed as shown in Table 1.

Table 4 shows the fitting results of pseudo-first-order, pseudo-second-order and Elovich kinetic models for TN release. Results 
TABLE 3 Release kinetics of $\mathrm{PO}_{4}^{3-}-\mathrm{P}$ from fish feed

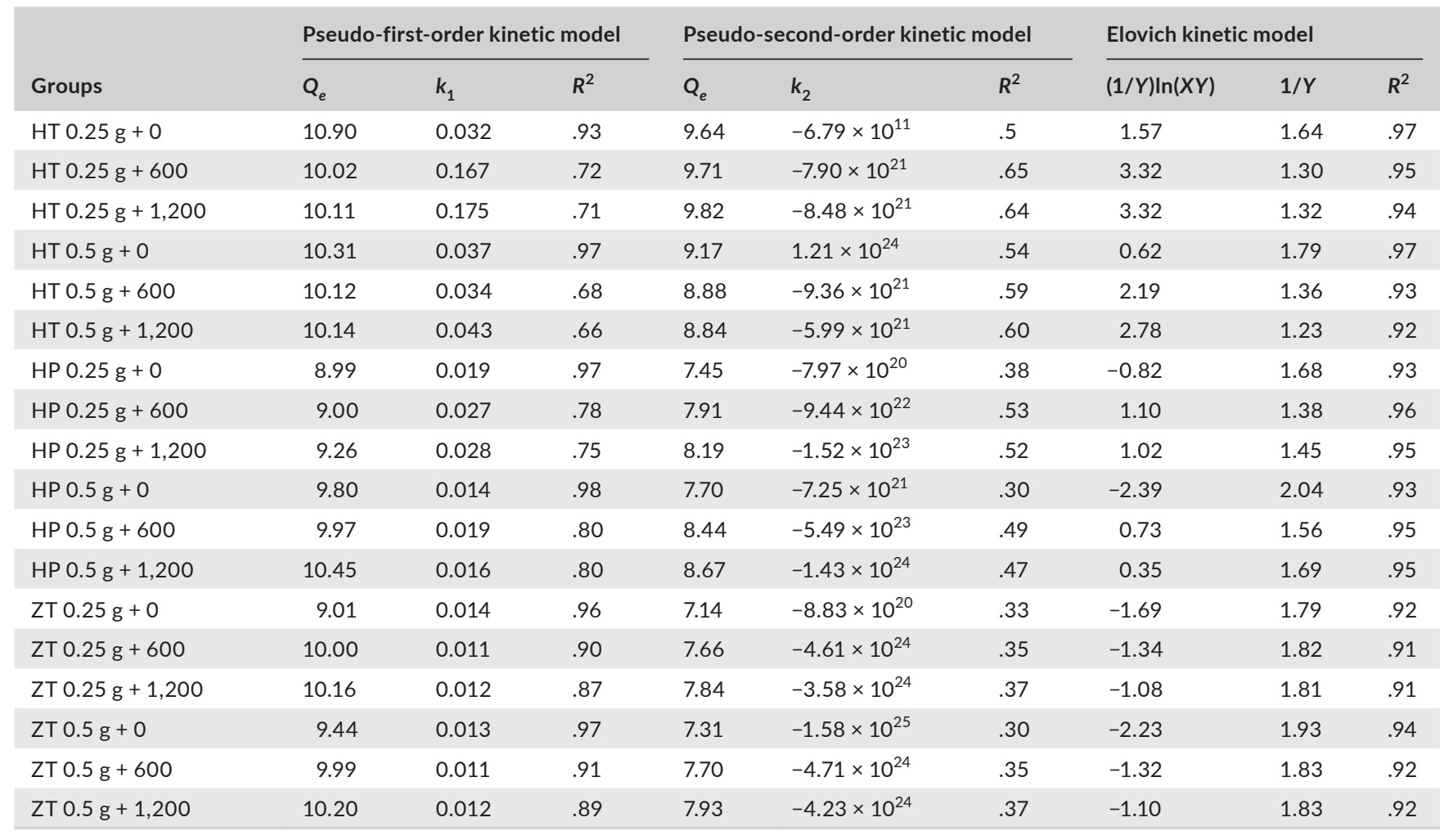

showed that pseudo-first-order and Elovich kinetic models $\left(R^{2}\right.$ is .89-.99 and .85-.99, respectively) can describe variations of released $\mathrm{TN}$ contents better than pseudo-second-order kinetic model $\left(R^{2}\right.$ is .23-.52). From Table 4, with same fish feed and dosage, both $k_{1}$ and $Q_{e-1}$ increase with increasing of stirring intensity, which indicates that the release rate and released TN contents can be improved by increasing stirring intensity. With same stirring intensity and fish feed dosage, $Q_{e-1}$ of $\mathrm{HT}$ is most, $Q_{e-1}$ of HP is next while $Q_{e-1}$ of ZT is smallest, and the results are consistent with measured results. In addition, according to parameters of Elovich model in Table $4,1 / Y$ is obviously higher than $(1 / Y) \ln (X Y)$, which means the process of $T N$ released from fish feed is mainly slow phase.

Variance analysis of the effect of stirring intensity, fish feed dosage and fish feed type on released TN concentrations and released TN contents are shown in Table S1. All of factors including stirring intensity, fish feed dosage and fish feed type have significant effects on released TN concentrations $(p<.05)$. Meanwhile, both stirring intensity and fish feed type have significant effects on released TN contents $(p<.05)$ while fish feed dosage has not $(p>.05)$. And there is no interaction among stirring intensity, fish feed dosage and fish feed type for both TN concentrations and TN contents $(p>.05)$ as shown in Table S1. The results of variance analysis for TN is consistent with that of TP, i.e. both hydraulic conditions and fish feed type are the main factors affecting released TN contents are related to regardless of fish feed dosage. In the present experiment, the concentrations (or contents) of TN released from fish feed was higher with stirring condition, and the stirring intensity has a significant impact on the released TN concentrations and contents. Chen, Zhao, and Sun (2007) and Fan et al. (2003) also found that resuspension of particulate matter promoted the release of large amounts of TN in the field experiment of marine and lakes.

\subsection{2 | Release kinetics of $\mathrm{NH}_{4}^{+}-\mathrm{N}$ from fish feed}

It is generally believed that the $\mathrm{NH}_{4}^{+}-\mathrm{N}$ release process is relatively complicated owing to the ammonization of organic nitrogen, the nitrification of ammonia nitrogen, the denitrification of nitrate nitrogen and the absorption of ammonia nitrogen by organic microorganisms. As shown in Figure 4, when the stirring intensity is 600 and 1,200 rpm, the fish feed is suspended in a large amount at the beginning of the experiment, and the released concentrations and contents of $\mathrm{NH}_{4}^{+}-\mathrm{Nincreased}$, and the concentrations and contents increased slowly and gradually became stable at the end of the experiment (from $300 \mathrm{hr}$ ), which is consistent with Wu et al.'s (2012) experimental results. According to Figures 1-4, it is obvious that the nitrogen $\left(\mathrm{TN}\right.$ and $\left.\mathrm{NH}_{4}^{+}-\mathrm{N}\right)$ release was slower than the phosphorus ( $\mathrm{TP}$ and $\mathrm{PO}_{4}^{3-}-\mathrm{P}$ ) release from fish feed. This is because labile form of phosphorus is directly added into fish feed and that make most of phosphorus can be released directly, while nitrogen is added into fish feed in forms of protein and lysine which has to be transformed in water before released. 
TAB LE 4 Release kinetics of TN from fish feed

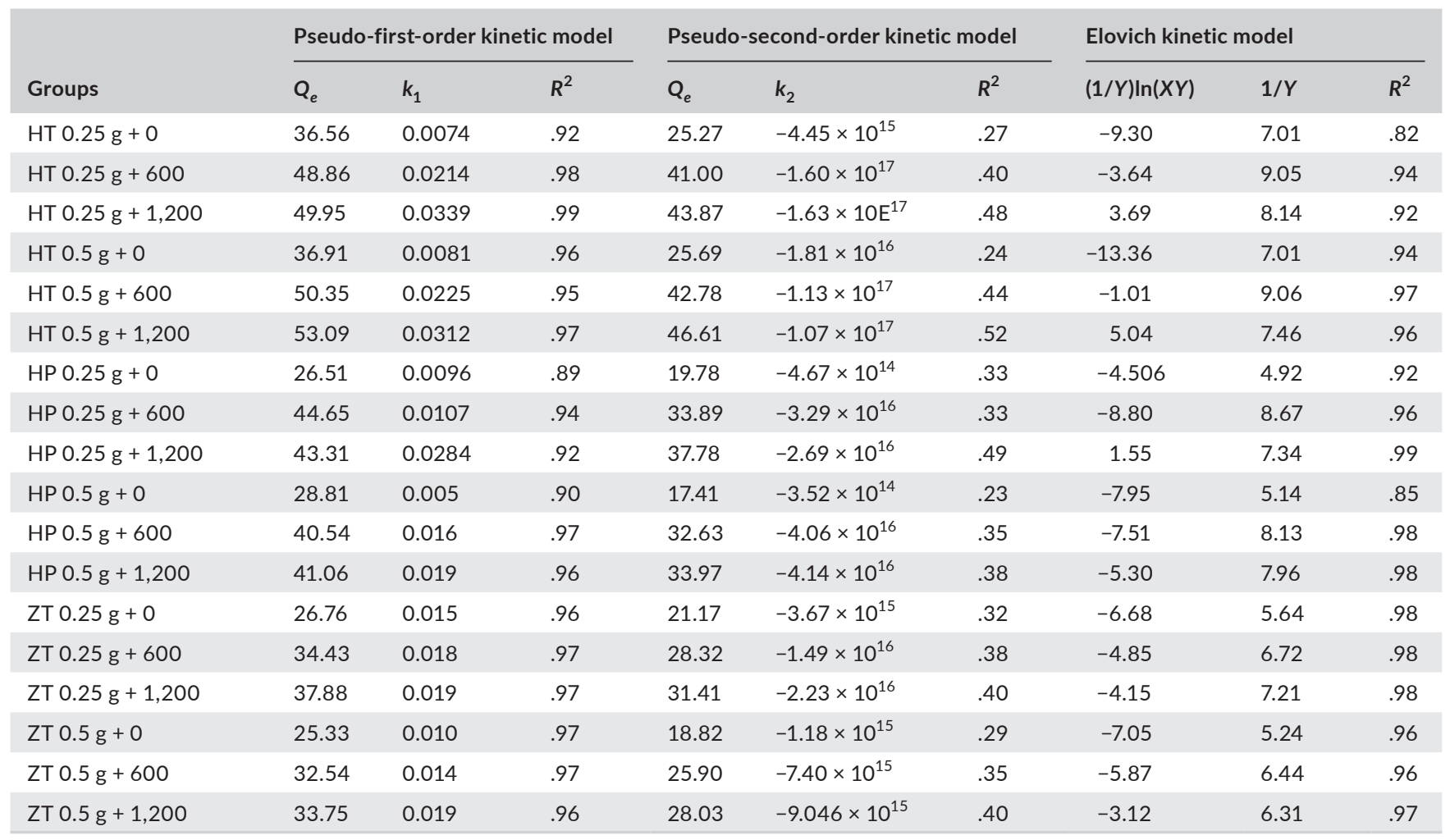

Both released $\mathrm{NH}_{4}^{+}-\mathrm{N}$ concentrations and released $\mathrm{NH}_{4}^{+}-\mathrm{N}$ contents of unit weight fish feed increase with increasing of stirring intensity, and released $\mathrm{NH}_{4}^{+}-\mathrm{N}$ concentrations and contents under stirring condition (1,200 and $600 \mathrm{rpm})$ are obviously higher than the released $\mathrm{NH}_{4}^{+}-\mathrm{N}$ concentrations and contents under non-stirring conditions ( 0 rpm). In Akhan and Gedik's (2011) study, ammonium release from fish food was slow in the first few days of experiments but ammonium release increased in later periods and reached the highest rate in day 11 , and it is basically consistent with our results. In Wang, Wang, and Wang (2010) experiment, the bed shear stress was reduced when the water flow structure was affected by plants, thereby reducing sediment suspension and $\mathrm{NH}_{4}^{+}-\mathrm{N}$ release. In addition, according to Figure 4 and Equation 1, released $\mathrm{NH}_{4}^{+}-\mathrm{N}$ concentrations in treatments with $0.5 \mathrm{~g}$ fish feed are nearly two times higher than those of treatments with $0.25 \mathrm{~g}$ fish feed, while released $\mathrm{NH}_{4}^{+}-\mathrm{N}$ contents in treatments with $0.5 \mathrm{~g}$ fish feed were quite close to those of treatments with $0.25 \mathrm{~g}$ fish feed.

Wang et al. (2007), Cao and Tao (1999), and Morin and Morse (1999) used first-order kinetic model to describe the release of $\mathrm{NH}_{4}^{+}-\mathrm{N}$ from sediments. In the present study, we try these kinetic models to describe the release of $\mathrm{NH}_{4}^{+}-\mathrm{N}$ from fish feed. As shown in Table 5, both pseudo-first-order and Elovich kinetic models can better describe variations of released
$\mathrm{NH}_{4}^{+}-\mathrm{N}$ contents of unit weight fish feed with $R^{2}=.94-.99$ and $R^{2}=.57-.94$, respectively, than pseudo-second-order model with $R^{2}=.034-.19$. From Table 5, with same fish feed dosage and type, $Q_{e-1}$ increases with increasing of stirring intensity; and with same fish feed dosage and stirring intensity, the order of $Q_{e-1}$ among three fish feed is $\mathrm{HT}>\mathrm{HP}>\mathrm{ZT}$. According to parameters of Elovich kinetic model, the release of $\mathrm{NH}_{4}^{+}-\mathrm{N}$ from fish feed mainly occurs in the slow release stage $(1 / Y$ is higher than $(1 / Y)$ $\ln (X Y))$, and $1 / Y$ increase with increasing of stirring intensity with same type and dosage of fish feed.

From Table S1, either stirring intensity or fish feed type has significant effects on both released $\mathrm{NH}_{4}^{+}-\mathrm{N}$ concentrations from fish feed and released $\mathrm{NH}_{4}^{+}-\mathrm{N}$ contents of unit weight fish feed $(p<.05)$, while fish feed dosage only does have significant effects on released concentrations $(p<.05)$. Meanwhile, there are no interaction among stirring intensity, fish feed dosage and fish feed type for released $\mathrm{NH}_{4}^{+}-\mathrm{N}$ concentrations and contents $(p>.05$ ). Thus, different with $\mathrm{NH}_{4}^{+}-\mathrm{N}$ concentrations, released $\mathrm{NH}_{4}^{+}-\mathrm{N}$ contents of unit weight fish feed is influenced by hydraulic conditions and the nature (type) of fish feed instead of fish feed dosage. In addition, as shown in Table $\mathrm{S} 3, \mathrm{NH}_{4}^{+}-\mathrm{N}$ is the main component of $\mathrm{TN}$, and the average released $\mathrm{NH}_{4}^{+}-\mathrm{N}$ concentrations are $54 \%-$ $74 \%$ of average released TN concentrations, and the maximum released $\mathrm{NH}_{4}^{+}-\mathrm{N}$ concentrations are $70 \%-88 \%$ of maximum released TN concentrations. 

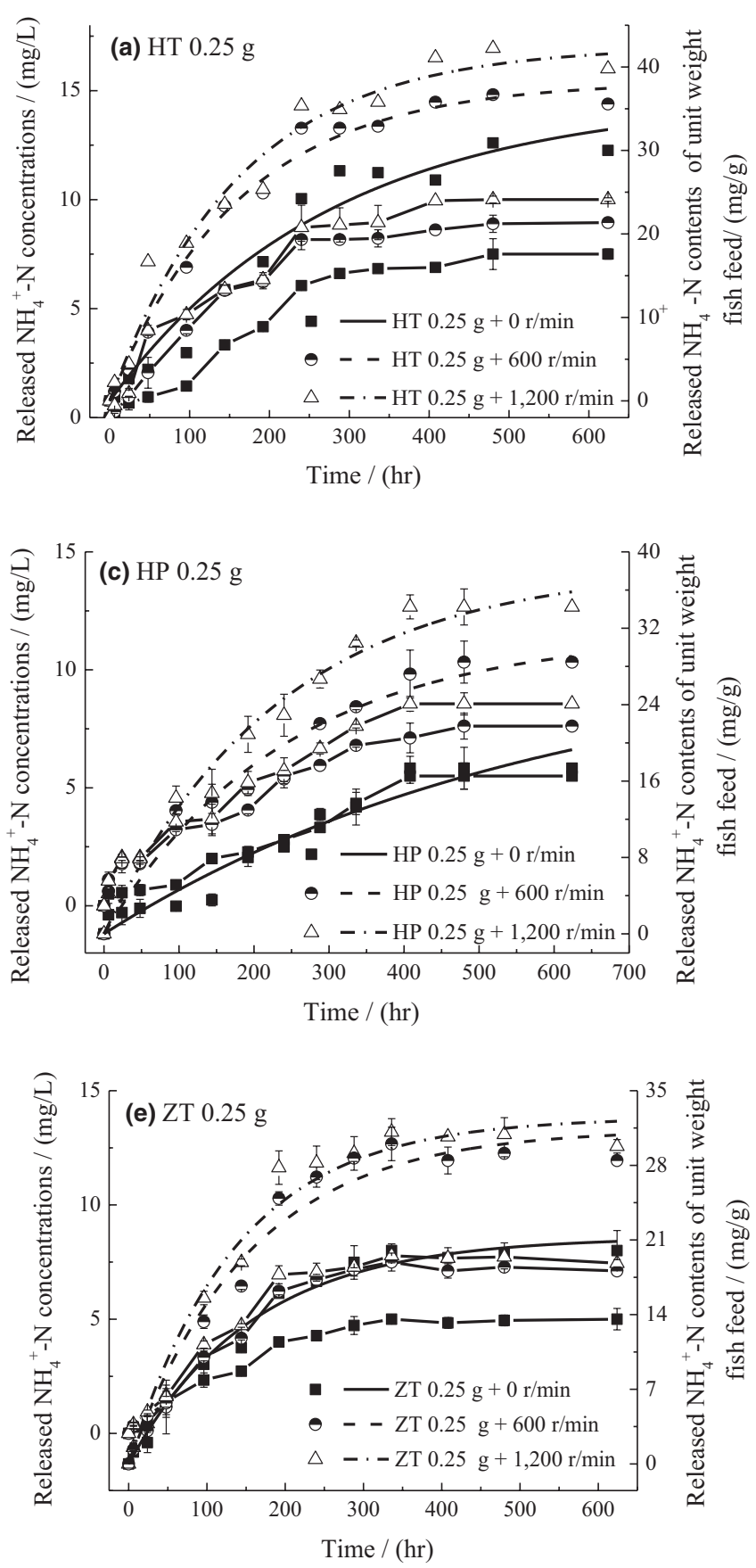

FIGURE 4 Pseudo-first-order kinetic of $\mathrm{NH}_{4}^{+}-\mathrm{N}$ from fish feed

\section{4 | CONCLUSIONS}

Effects of stirring intensity, fish feed dosage and fish feed type on aquaculture water environment is investigated in the present study. The two main conclusions can be drawn as follows.

1. Released TP, $\mathrm{PO}_{4}^{3-}-\mathrm{P}, \mathrm{TN}$ and $\mathrm{NH}_{4}^{+}-\mathrm{N}$ contents of unit weight fish feed can be described by pseudo-first-order, pseudo-second-order and Elovich kinetic models, in which the fitting results of Elovich and pseudo-first-order kinetic models are more valid. From parameters of Elovich model, the release of TP from fish
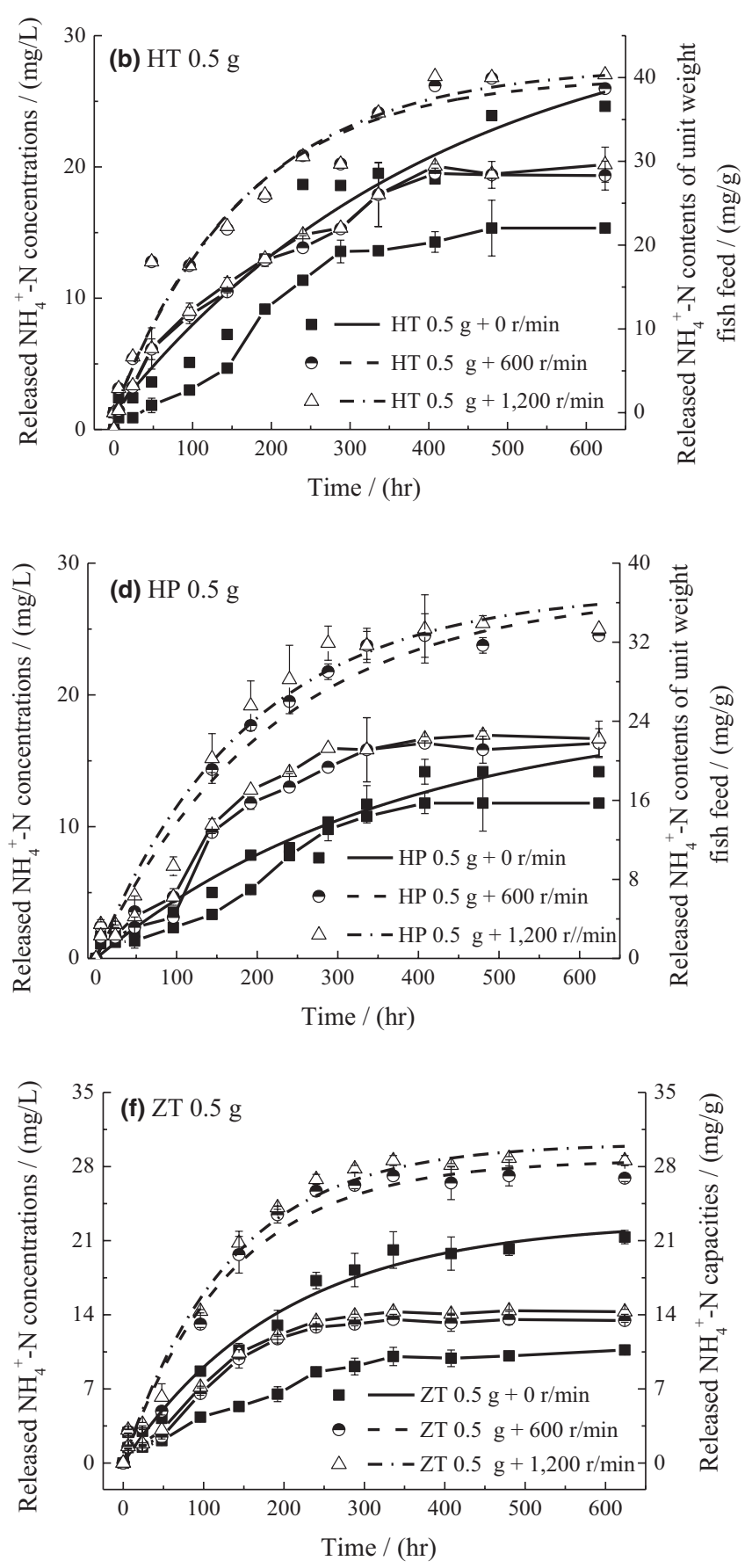

feed mainly happens in fast phase, and the release of TN and $\mathrm{NH}_{4}^{+}-\mathrm{N}$ mainly happens in slow phase. However, affected by stirring intensity and fish feed type, the release process of $\mathrm{PO}_{4}^{3-}-\mathrm{P}$ from $\mathrm{HT}$ fish feed in static water is dominated by fast release, while the release process of $\mathrm{PO}_{4}^{3-}-\mathrm{P}$ in other conditions is mainly dominated by slow release. In addition, $\mathrm{PO}_{4}^{3-}-\mathrm{P}$ and $\mathrm{NH}_{4}^{+}-\mathrm{N}$ is the main component of TP and TN respectively.

2. Variance analysis shows that stirring intensity and fish feed type have significant effects on both released concentrations and contents of TP, $\mathrm{TN}$ and $\mathrm{NH}_{4}^{+}-\mathrm{N}(p<.05)$, stirring intensity and fish 
TAB LE 5 Release kinetics of $\mathrm{NH}_{4}^{+}-\mathrm{N}$ from fish feed

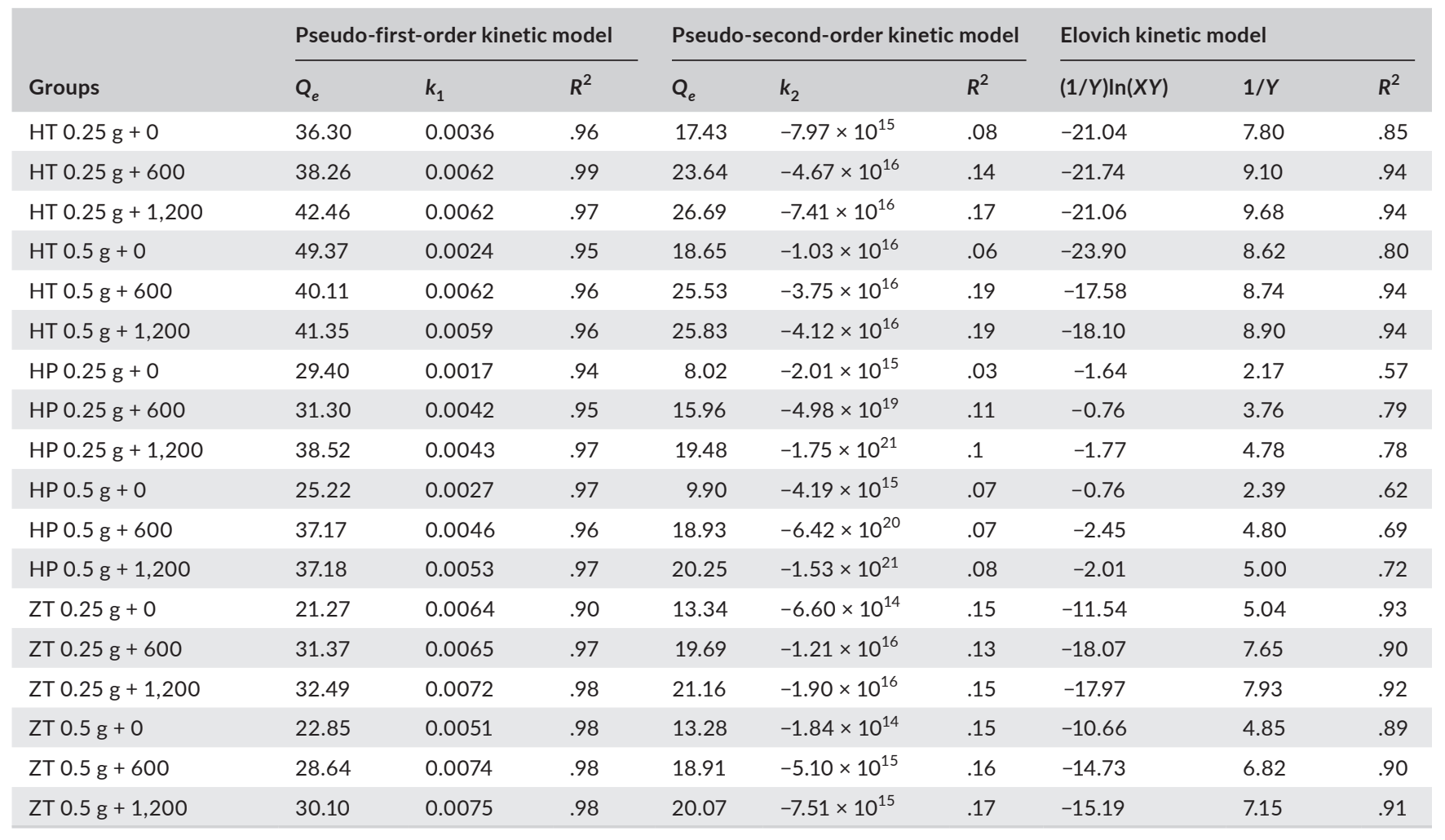

feed type also have significant effects on released $\mathrm{PO}_{4}^{3-}-\mathrm{P}$ concentrations $(p<.05)$ but only fish feed type do have significant effects on the released $\mathrm{PO}_{4}^{3-}-\mathrm{P}$ contents of unit weight fish feed $(p<.05)$. In addition, released concentrations of TP, $\mathrm{PO}_{4}^{3-}-\mathrm{P}, \mathrm{TN}$ and $\mathrm{NH}_{4}^{+}-\mathrm{N}$ also can be influenced by fish feed dosage $(p<.05)$, while released $\mathrm{TP}, \mathrm{PO}_{4}^{3-}-\mathrm{P}, \mathrm{TN}$ and $\mathrm{NH}_{4}^{+}-\mathrm{N}$ contents cannot be influenced $(p>.05)$.

\section{ACKNOWLEDGMENTS}

The study is financially supported by the National Natural Science Foundation of China (11672139, 5181101344, and 4181101396), the Natural Science Foundation of Tianjin (18YFZCSF00510) and China-poland science and technology cooperation committee regular meeting exchange programme (37-14).

\section{CONFLICT OF INTEREST}

The authors declare no competing financial interests.

\section{AUTHOR CONTRIBUTION}

S. L. Huang, W. W. Kong and F. F. Shi conceived the research and designed the experiments; W. W. Kong, F. F. Shi and Y. B. Feng performed the experiments; W. W. Kong and S. L. Huang formulated all equations; S. L. Huang, W. W. Kong, F. F. Shi, Y. B. Feng and Z. J. Yang analysed the data; W. W. Kong and S. L. Huang wrote the article, S. L. Huang supervised and edited the manuscript. Z. Khatoon and J. G.
Zhou polished the English. All authors read and approved the final manuscript. All authors agree to authorship and submission of the manuscript for peer review.

\section{STATEMENT OF INFORMED CONSENT, HUMAN/ ANIMAL RIGHTS}

No conflicts, informed consent, human or animal rights applicable.

\section{DATA AVAILABILITY STATEMENT}

All data generated or analysed during this study are included in this article.

\section{ORCID}

Suiliang Huang (iD https://orcid.org/0000-0002-4170-4368

\section{REFERENCES}

Ackefors, H., \& Enell, M. (1994). The release of nutrients and organic matter from aquaculture systems in Nordic countries. Journal of Applied Ichthyology, 10(4), 225-241.

Akhan, S., \& Gedik, K. (2011). The nutrient releases from sea bass (Dicentrarchus labrax Linnaeus, 1758) faeces and food in estuarine Black Sea condition. Journal of Food Agriculture \& Environment, 9(1), 738-740.

Amirkolaie, A. K. (2011). Reduction in the environmental impact of waste discharged by fish farms through feed and feeding. Reviews in Aquaculture, 3(1), 19-26.

Bartozek, E. C., Bueno, N. C., Feiden, A., \& Rodrigues, L. C. (2016). Response of phytoplankton to an experimental fish culture in net cages in a subtropical reservoir. Brazilian Journal of Biology, 76(4), 824-833. 
Borges, P. A. F., Train, S., Dias, J. D., \& Bonecker, C. (2010). Effects of fish farming on plankton structure in a Brazilian tropical reservoir. Hydrobiologia, 649(1), 279-291.

Cao, J., \& Tao, S. (1999). Release kinetics of organic carbon from soil and sediment. Acta Scientiae Circumastantiae, 19(3), 22-26.

Chao, J. Y., Guang, G., Tang, X. M., Dai, J. Y., Zhuang, W., \& Zhang, Y. M. (2011). Effects of Wind-Induced wave on organic arrogates physical and chemical characteristics in a shallow eutrophic lake (Lake Taihu) in China. Environmental Science, 32(10), 2861-2867.

Chen, J., Zhao, J., Sun, Y., \& Fang, J. G. (2007). Dynamic mechanism of sediment resuspension with its effects on content of nutrients in water in the shellfish culture area of Sanggou Bay. Marine Fisheries Research, 28(3), 105-111.

Chien, S. H., \& Clayton, W. R. (1980). Application of Elovich equation to the kinetics of phosphate release and sorption in soils. Soil Science Society of America Journal, 44(2), 265-268.

China's State Environmental Protection Administration (2002). Water and wastewater monitoring and analysis method (4th ed.). Beijing, China: China Environmental Science Press.

Fan, C. X., Zhang, L., Qin, B. Q., Wang, S. M., Hu, W. P., \& Zhang, C. (2003). Dynamic release estimation of phosphorus in suspended particulates from Taihu Lake under wind and wave. Science in China (Series D), 33(8), 760-768.

Fernandes, M., Angove, M., Sedawie, T., \& Cheshire, A. (2007). Dissolved nutrient release from solid waste of southern blue tuna (Thunnus maccoyii, Castelnau) aquaculture. Aquaculture Research, 38, 388-397.

Gao, Q. F., Xu, W. Z., Liu, X. S., Cheung, S., \& Shin, P. (2008). Seasonal changes in $C, N$ and $P$ budgets of green-lipped mussels Perna viridis and removal of nutrients from fish farming in Hong Kong. Marine Ecology Progress, 353(01), 137-146.

Gao, Y. X., Sun, X. J., Zhang, Z. P., Zhu, G.-W., \& Pang, Y. (2007). Simulated study on concentration change of different form phosphorus in shallow lakes caused by wind-wave disturbance. Advances in Water Science, 18(5), 668-673.

Geng, N., Wang, P. F., Wang, C., Qi, N., \& Wang, Z. Y. (2015). The impact of Vallisneria natans $L$. on the release of phosphorus from sediment under static and hydrodynamic conditions. Journal of Lake Science, 27(4), 637-642.

Gera, G. S., Yewalkar, S. N., Nene, S., Kulkarni, B. D., \& Kamble, S. (2016). Kinetic studies on an algal biofilm reactor for raw sewage water treatment. Chemical Engineering Technology, 39(9), 1629-1635.

Ho, Y. S. (2006a). Review of second-order models for adsorption systems. Journal of Hazardous Materials, B136, 681-689.

Ho, Y. S. (2006b). Second-order kinetic model for sorption of cadmium onto tree fern: A comparison of linear and non-linear methods. Water Research, 40, 119-125.

Hua, K., \& Bureau, D. P. (2006). Modelling digestible phosphorus content of salmonid fish feeds. Aquaculture, 254(1-4), 455-465.

Huang, J., Xi, B. D., Xu, Q. J., Wang, X., Li, W., He, L., \& Liu, H. (2016). Experiment study of the effects of hydrodynamic disturbance on the interaction between the cyanobacterial growth and the nutrients. Journal of Hydrodynamics, 28(3), 411-422.

Huang, J., Xu, Q. J., Xi, B. D.,Wang, X., Li, W., Gao, G., ... Jia, K. (2015). Impacts of hydrodynamic disturbance on sediment resuspension, phosphorus and phosphatase release, and cyanobacterial growth in Lake Tai. Environmental Earth Sciences, 74(5), 3945-3954.

Huang, S. L. (2001). Cadmium adsorption by sediment in a turbulence tank. Water Research, 35(11), 2635-2644.

Huang, S. L. (2003). Investigation of cadmium desorption from different sized sediments. Journal of Environmental Engineering, 129(3), 241-247. https://doi.org/10.1061/(ASCE)0733-9372(2003)129: $3(241)$

Huang, S. L., \& Kong, W. W. (2017). Incubator experiments on the effect of atrazine on the growth process of Microcystis aeruginosa and analysis of nutrient variation. Ecology and Environmental Science, 26(11), 1950-1960.

Huang, S. L., Kong, W. W., Yang, Z. J., Yu, H., \& Li, F. Y. (2019). Combination of Logistic and modified Monod functions to study Microcystis aeruginosa growth stimulated by fish feed. Ecotoxicology and Environmental Safety, 167, 146-160.

Huang, S. L., Wu, M., Zang, C. J., Du, S. L., Domagalski, J., Gajewska, M., ... Szymkiewicz, R. (2016). Dynamics of algae growth and nutrients in experimental enclosures culturing bighead carp and common carp: Phosphorus dynamics. International Journal of Sediment Research, 31, 173-180.

Kibria, G., Nugegoda, D., Fairclough, R., \& Lam, P. (1997). The nutrient content and the release of nutrients from fish food and faeces. Hydrobiologia, 357, 165-171.

Liu, J. S., Cui, Y. B., \& Liu, J. K. (1997). Advances in studies on the effect of cage culture on the environment. Acta Hydrobiologica Sinica, 21(2), 174-184.

Morin, J., \& Morse, J. W. (1999). Ammonium release from resuspended sediments in the Laguna Madre estuary. Marine Chemistry, 65, 97110. https://doi.org/10.1016/S0304-4203(99)00013-4

Nędzarek, A., Tórz, A., \& Stepanowska, K. (2009). The influence of intensive fish nutrition on the quality of cooling waters. Oceanological and Hydrobiological Studies, 38(3), 51-59.

Penczak, T., Galicka, W., Molinski, M., Kusto, E., \& Zalewski, M. (1982). The enrichment of a mesotrophic lake by carbon, phosphorus and nitrogen from the cage aquaculture of Rainbow Trout, Salmo gairdneri. Journal of Applied Ecology, 19(2), 371-393.

Qian, J. Z., Chu, Q. Y., Zhang, R. G., Liu, Y., \& Wan, W. H. (2019). Influence of recurrent rainfall and oxalic acid on phosphorus releasing from rocks phosphate in the Chaohu watershed, China. Chemosphere, 215, 815-826.

Ranjbar, F., \& Jalali, M. (2014). Empirical and mechanistic evaluation of $\mathrm{NH}_{4}{ }^{+}-\mathrm{N}$ release kinetic in calcareous soils. Archives of Environment Contamination and Toxicology, 66, 606-615.

Shariatmadari, S. H., \& Jafari, M. (2006). Phosphorus release kinetics and availability in calcareous soils of selected arid and semiarid toposequences. Geoderma, 132(3), 261-272.

Sun, X. J., Qin, B. Q., Zhu, G. W.,Zhang, Z. P., \& Gao, Y. X. (2007). Release of colloidal $\mathrm{N}$ and $\mathrm{P}$ from sediment of lake caused by continuing hydrodynamic disturbance. Environmental Science, 28(6), 1223-1229.

Sun, Y. J., Lu, S. Q., Lin, W. Q., Wang, D. Z., Fan, J. Y., \& Li, Z. (2016). In-situ study on nutrient release fluxes from shallow lake sediments under wind-driven waves. Journal of Hydrodynamics, 28(2), 247-254.

Wang, C., Wang, C., \& Wang, Z. (2010). Effects of submerged macrophytes on sediment suspension and $\mathrm{NH}_{4}{ }^{+}-\mathrm{N}$ release under hydrodynamic conditions. Journal of Hydrodynamics, 22(6), 810-815. https:// doi.org/10.1016/S1001-6058(09)60120-7

Wang, J. Q., Shen, Y. H., \& Ma, Y. P. (2010). Release kinetics of rock phosphorus in the Chaohu Lake area. Acta Scientiae Circumstantiae, 30(5), 979-984.

Wang, J., Wang, S. R., Jin, X. C., Zhang, Y. J., \& Zhu, S. Q. (2007). Effect of submerged aquatic plant Hydrilla verticilla on the sorption/release characteristic of ammonia nitrogen on sediment. Ecology and Environment, 16(2), 336-341.

Wang, W. Q., Wen, Y. M., \& Chai, S. W. (2004). Nitrogen Forms, distribution and environmental impacts in the sediment of aquacultural water column. Fisheries Science, 23(1), 29-33.

Wang, X. X., Andresen, K., Handa, A., Jensen, B.,Reitan, K. I., \& Olsen, Y. (2013). Chemical composition and release rate of waste discharge from an Atlantic salmon farm with an Atlantic salmon farm with an evaluation of IMTA feasibility. Aquaculture Environment Interactions, 4, 147-162.

Wen, Z. L., Zhang, A. J., \& Wen, Y. M. (2000). Impact of intensive freshwater aquaculture on water environment. Water Conservancy, 20(4), 19-20. 
Wu, M., Huang, S. L., Zang, C. J., Du, S. L., \& Scholz, M. (2012). Release of nutrient from fish food and effects on Microcysitis aeruginosa growth. Aquaculture Research, 43(10), 1460-1470.

Xia, B., Zhang, Q. H., Jiang, C. B., \& Nie, X. B. (2014). Experimental investigation of effect of flow turbulence on phosphorus release from lake sediment. Journal of Sediment Research, 1, 74-80.

Xia, B., Zhang, Q. H., Nie, X. B.,Huang, X.-Y., \& Chen, S.-X. (2014). Experimental and numerical investigation of the effects of turbulence on phosphorus release from sediment. China Environmental Science, 34(1), 97-104.

Xiao, Y., Cheng, H. K., Tang, H. W., \& Li, Z. W. (2015). Review of influence of hydrodynamic action on distribution of pollutants in water and sediment in river. Journal of Hohai University (Natual Science), 43(5), 480-488.

You, B., Zhong, J., Fan, C., Wang, T., Zhang, L., \& Ding, S. (2007). Effects of hydrodynamics process on phosphorus fluxes from sediment in large, shallow Taihu Lake. Journal of Environmental Science, 19, 1055-1060.

Zhang, M., Gu, Q. H., Li, X. J., Song, D. Y., \& Zhou, C. J. (2015). Phosphorus cycling in intensive grass carp culture. Fisheries Science, 34(8), 491-496.
Zhu, G. W., Qin, B. Q., \& Gao, G. (2004). Vertical distribution of the concentrations of phosphorus and suspended solid in Taihu lake affected by wind-induced wave. Advances in Water Science, 1515(6), 775-780.

\section{SUPPORTING INFORMATION}

Additional supporting information may be found online in the Supporting Information section.

How to cite this article: Kong W, Huang S, Shi F, et al. Study on release kinetics of nitrogen and phosphorus from fish feed.

Aquac Res. 2020;51:3216-3229. https://doi.org/10.1111/ are.14656 